\title{
The Development and Verification of a Novel ECMS of Hybrid Electric Bus
}

\author{
Jun Wang, Qing-nian Wang, Peng-yu Wang, and Xiao-hua Zeng \\ State Key Laboratory of Automotive Simulation and Control, Jilin University, Changchun 130025, China \\ Correspondence should be addressed to Peng-yu Wang; wpy123456789000@sohu.com
}

Received 20 December 2013; Revised 16 January 2014; Accepted 21 January 2014; Published 18 March 2014

Academic Editor: Ali Davoudi

Copyright (c) 2014 Jun Wang et al. This is an open access article distributed under the Creative Commons Attribution License, which permits unrestricted use, distribution, and reproduction in any medium, provided the original work is properly cited.

\begin{abstract}
This paper presents the system modeling, control strategy design, and hardware-in-the-loop test for a series-parallel hybrid electric bus. First, the powertrain mathematical models and the system architecture were proposed. Then an adaptive ECMS is developed for the real-time control of a hybrid electric bus, which is investigated and verified in a hardware-in-the-loop simulation system. The ECMS through driving cycle recognition results in updating the equivalent charge and discharge coefficients and extracting optimized rules for real-time control. This method not only solves the problems of mode transition frequently and improves the fuel economy, but also simplifies the complexity of control strategy design and provides new design ideas for the energy management strategy and gear-shifting rules designed. Finally, the simulation results show that the proposed real-time A-ECMS can coordinate the overall hybrid electric powertrain to optimize fuel economy and sustain the battery SOC level.
\end{abstract}

\section{Introduction}

In recent years, vehicle fuel consumption and air pollution emissions have attracted growing attention. In order to solve these problems, a tremendous amount of effort is directed toward hybrid power vehicle's driving systems that have a significant potential in fuel saving and emissions reduction. Meanwhile, a large number of hybrid electric vehicles have become available in the markets, which were considered to be the most promising vehicles to replace conventional enginedriven vehicles.

The improvements in fuel economy and the reductions in emissions of hybrid electric vehicles (HEV) mainly depend upon the energy management strategy (EMS); therefore, substantial research efforts have been carried out. The research methods can be classified into three categories: first, rulebased controls such as logic threshold control and finite state machine [1,2]; second, intelligent control algorithms such as model predictive control [3], fuzzy logic $[4,5]$, and neural networks [6]; third, optimal theory methods such as minimum theory, deterministic dynamic programming (DP) $[7,8]$, and stochastic DP (SDP) [9].
Rule-based control strategy is also named as the baseline control, which is a steady state optimization method through engineering experience and a simple analysis of the efficiencies of components such as engine, motor, and battery.

Intelligent control algorithm depends on experts' knowledge to be coded into control rules, and this method has good robustness and does not need to build complex control model. However, both the rule-based control and the fuzzy logic control strategy need to be predetermined and can only be optimized for a specific drive cycle [10-12].

Optimal energy management control strategy includes DP, SDP, and Pontryagin minimum principle (PMP) [13]. DP control algorithm is often used to obtain global optimal solutions for various types of HEV under the certain drive cycles, but it should know the future drive cycle information in advance. Therefore, DP control algorithm is impossible to be applicable in real-time control system, which is often used as a reference for energy management strategy design [14]. In order to optimize the torque distribution in real-time, SDP control algorithm has been proposed, which applies the current road and traffic information to predict future 
TABLE 1: Main specifications of the vehicle.

\begin{tabular}{lc}
\hline Item & Value \\
\hline Curb/gross weight $(\mathrm{kg})$ & $11500 / 18000$ \\
Frontal area $\left(\mathrm{m}^{2}\right)$ & 7.21 \\
Drag coefficient & 0.585 \\
Wheel base $(\mathrm{m})$ & 6.1 \\
Dynamic rolling radius $(\mathrm{m})$ & 0.512 \\
\hline
\end{tabular}

route information for EMS so as to acquire the ideal results. However, trip-based control approach is a major drawback of curse of dimensionality, which limits their application for real-time implementation.

The equivalent consumption minimization strategy (ECMS) is the most commonly used optimization method for real-time HEV energy management [15-17]. It is considered as suboptimal control method for HEV, since the fuel economy deviation between ECMS and DP control algorithm was verified to be less than $1.2 \%$ [18]. Therefore, in this study, ECMS is chosen as the online energy management strategy to optimize torque distribution and gear-shift rules.

Then the novel ECMS was verified in the hardware-inthe-loop (HIL) simulator for its high real-time performance and high precision. Not only can the HIL simulation verify the effectiveness of the control strategy, but it can also optimize its control parameters $[19,20]$. Hardware-in-the-loop simulation is the trusted method to put ECU functions, ECU bus communication, and integrated ECUs to the test. The tests are performed in a simulated environment, meaning that the HIL simulator makes the ECU believe that it is located in a real vehicle driving somewhere. This way the simulator can test the ECU's reaction to specific situations, and you can move tedious, expensive, and sometimes even dangerous driving tests from the actual vehicle into the laboratory [21]. In this way, the control functions and performance of the HCU of the series-parallel hybrid bus can be tested and improved.

\section{System Architecture}

The HEV control algorithm is to regulate the operation of powertrain system to achieve the optimal fuel economy and emissions performance under the different drive cycles, while meeting drivability requirements and sustaining the battery SOC level [22]. Moreover, the development of HEV control algorithm is based on the specific powertrain configuration. Basic parameters of the hybrid electric bus (HEB) are listed in Table 1.

The proposed HEV powertrain consists of a 4-cylinder Deutz diesel engine, an M1 motor, an M2 motor, an automated mechanical transmission (AMT), a torque coupler, and an electronically controlled clutch. The main specifications of the powertrain components are listed in Table 2. In this powertrain, the engine is directly connected to the input shaft of the clutch, the M1 motor is attached to the input shaft of the AMT, and the M2 motor couples the shaft via the torque coupler at a constant gear ratio. The novel hybrid driving system is to coordinate engine output power by M2 motor in the low-speed conditions and to coordinate engine output power by M1 motor in the high-speed conditions, so as to improve the fuel economy and keep dynamic performance. According to the structural characteristics of hybrid driving system, the drive mode can be divided into pure electric mode, series mode, engine-driven alone, parallel mode 1 (engine and M2 motor combined driving), and parallel mode 2 (engine and M1 motor combined driving). This series-parallel HEB powertrain was shown in Figure 1.

This paper provided adaptive equivalent minimum fuel consumption control algorithm through driving cycle recognition to update the equivalent fuel consumption coefficient and then to get the optimal torque distribution and gearshift rules. Figure 2 describes the TCU and HCU integration control flowchart.

$T_{\text {req }}$ is the torque requirement, $V_{\text {veh }}$ is the vehicle actual velocity, $V_{\operatorname{tar}}$ is the target velocity, $T_{e}$ is the engine torque, $T_{m 1}$ is the M1 motor torque, $T_{m 2}$ is the M2 motor torque, $i_{g(n)}$ is the transmission ratio, and $R_{\text {cluth }}$ is the clutch signal.

\section{Powertrain Models}

3.1. Engine Model. The engine operation status is very complicated which makes it hard to establish a precise simulation model by maths model and theoretical formula. In this paper, the engine model is simplified as static maps that are used to calculate the engine torque output and the fuel consumption. But the engine BSFC map may only give steadystate fuel consumption when engine is operating at normal temperature, since the engine may often operate in transient conditions that would consume more fuel than steadystate engine fuel consumption. So it should be corrected to obtain the transient-state fuel consumption according to the experimental data [23]:

$$
\begin{gathered}
T_{e}=T_{e}\left(a_{e}, \omega_{e}\right)-T_{\mathrm{fl}}\left(\omega_{e}\right), \\
g_{e}=f_{\text {fuel }}\left(T_{e}, \omega_{e}\right), \\
g_{e, f}=g_{e}\left[1+f_{1}\left(t_{e m}\right)+f_{2}^{\prime}\left(\alpha_{e}^{\prime}\right)\right],
\end{gathered}
$$

where $a_{e}$ is the actual load of engine, $\omega_{e}$ is the engine speed, $T_{\mathrm{fl}}$ is the engine resistant torque, $g_{e}$ is the engine steady fuel consumption, $f_{1}$ is the fuel consumption increase rate due to engine warm-up, $f_{2}^{\prime}$ is the fuel consumption increase rate due to the engine load increasing rate, $t_{e m}$ is the engine operating temperature, $\alpha_{e}^{\prime}$ is the engine load increasing rate, and $g_{e, f}$ is the engine transient fuel consumption.

3.2. Electric Motor Model. Electric motor is used to provide electric propelling power and energy recycling for fuel economy improvement. This paper mainly concerns motor external characteristics: maximum motor torque, minimal motor torque, and efficiency map. A simple lookup table is 
TABLE 2: Vehicle basic parameters.

\begin{tabular}{lcc}
\hline Powertrain & Parameters & Product model \\
\hline Engine power rating & $121 \mathrm{~kW} / 2500 \mathrm{r} / \mathrm{min}$ & Deutz, BF4M1013FC \\
M1 motor rated power/peak power & $30 / 50 \mathrm{~kW}$ & Shanghai eDrive TYC-168-260-8-C \\
M2 motor rated power/peak power & $58 / 116 \mathrm{~kW}$ & ENOVA, M10000DA \\
Battery voltage/capacity & $336 \mathrm{~V} / 80 \mathrm{Ah}$ & Chunlan, DY336-40 \\
Six speed gearbox transmission ratios & $7.285,4.193,2.485,1.563,1$, and 0.847 & FAW, CA5-85 AMT \\
Main reducer gear ratio & 6.333 & - \\
Coupler gear ratio & 3.8 & - \\
\hline
\end{tabular}

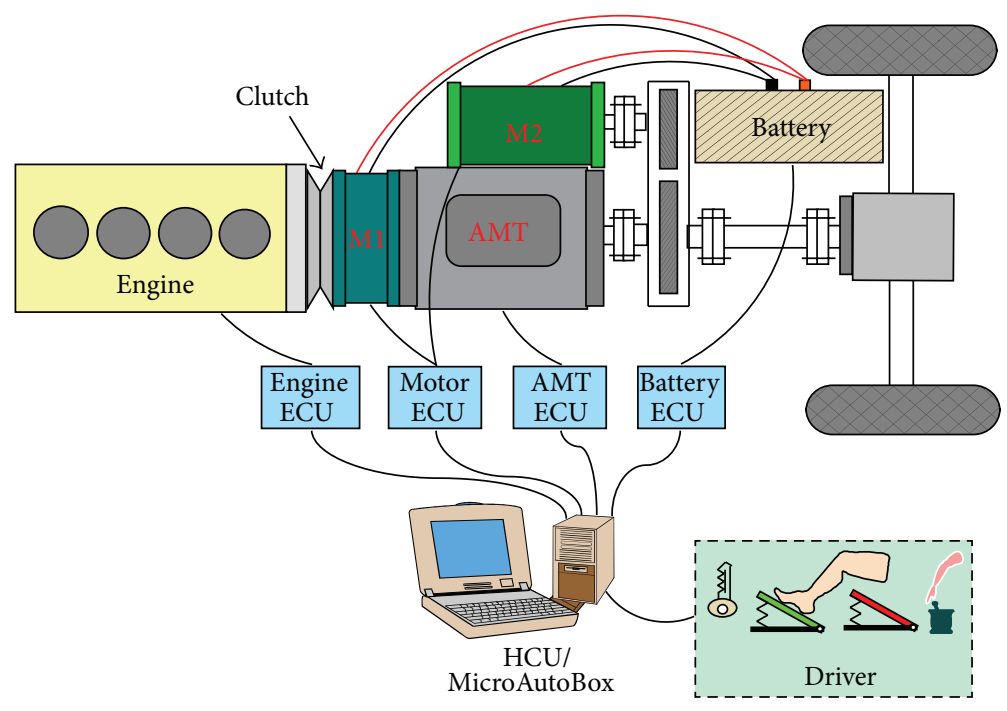

FIgURE 1: Schematic of a series-parallel HEB powertrain.

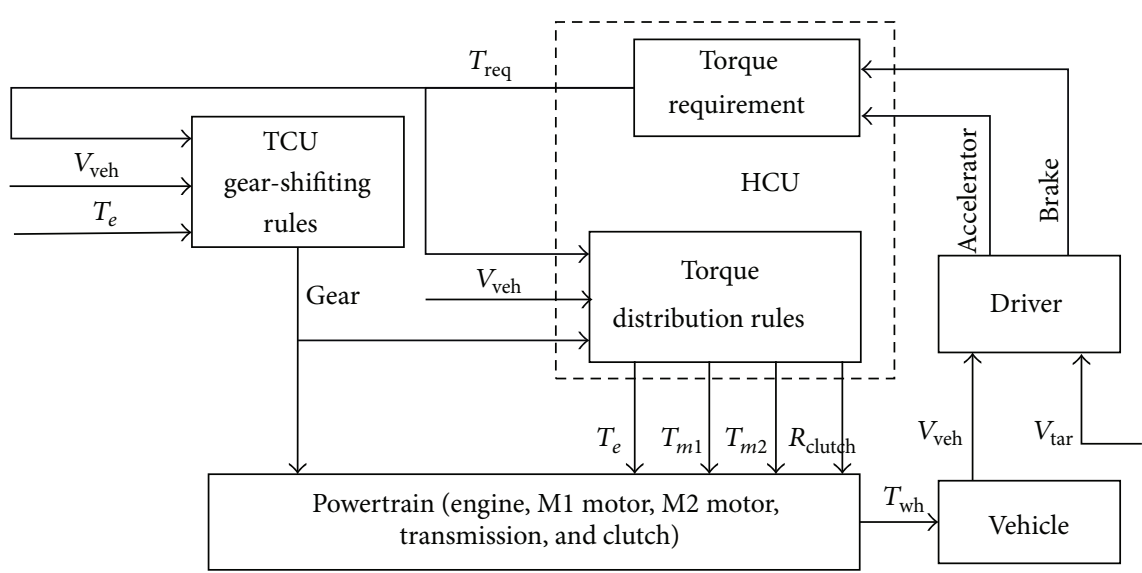

FIGURE 2: The integrated control flowchart of gear-shifting rules and energy management.

adopted to characterize the motor efficiency depending on the motor speed and torque and terminal voltage [24]:

$$
\begin{gathered}
T_{m}=T_{m \_ \text {max }}\left(n_{m}, U_{m}\right) \cdot a_{m}, \\
\eta_{m}=\eta\left(n_{m}, T_{m}\right),
\end{gathered}
$$

$$
\begin{gathered}
P_{m}= \begin{cases}\frac{T_{m} \cdot n_{m}}{\eta_{m}} ; & \left(T_{m} \geq 0\right) \\
T_{m} \cdot n_{m} \cdot \eta_{m} ; & \left(T_{m}<0\right),\end{cases} \\
I_{m}=\frac{P_{m}}{U_{m}},
\end{gathered}
$$


where $T_{m_{-} \text {max }}$ is the motor maximum torque, $a_{m}$ represents percentage of full load torque, $n_{m}, T_{m}$, and $U_{m}$ are the motor speed, motor torque, and motor's terminal voltage, $\eta_{m}$ is the motor efficiency, $I_{m}$ is the motor current, and $P_{m}$ is the motor power.

3.3. Battery Model. There were a lot of battery modeling approaches that have been introduced; among them, PNGV battery model [25] can accurately simulate the dynamic characteristics of the battery, but this modeling focus is the powertrain dynamics in a system level rather than the internal battery dynamics; hence the Rint model [26] was used to calculate the battery open-circuit voltage, the internal resistance, and the battery SOC.

$$
\begin{gathered}
U_{b}=U_{0}(\mathrm{SOC}) \cdot N_{b}, \\
R_{b}=R_{0}(\mathrm{SOC}) \cdot N_{b}, \\
\mathrm{SOC}=\mathrm{SOC}_{0}+\frac{1}{3600 \cdot C} \int_{t_{0}}^{t} I_{b} d t, \\
I_{b}=\frac{U_{b}-\sqrt{U_{b}^{2}-4 R_{b} P_{b}}}{2 R_{b}},
\end{gathered}
$$

where $N_{b}$ is the number of battery cells, $U_{b}$ is the battery open-circuit voltage, $R_{b}$ is the battery internal resistance, $I_{b}$ is the battery current, $P_{b}$ is the battery power, SOC is the battery state of charge, $\mathrm{SOC}_{0}$ is the battery initial SOC, and $C$ is the battery capacity.

3.4. Clutch Model. The clutch model is composed of three modes: sliding mode, engagement mode, and disengagement mode. The operating mode of the clutch is determined by the displacement of clutch release $S_{c}$ and the relative speed of the clutch $n_{c, \text { rel }}$. The transmitted torque of the clutch $T_{\mathrm{cl}}$ can be calculated by the following equation [27]:

$$
\begin{aligned}
& T_{\mathrm{cl}} \\
& =\left\{\begin{array}{c}
-F_{C, \mathrm{act}} \cdot N_{C} \cdot \mu_{C, \mathrm{st}} \cdot r_{c, m} ; \\
\left(\left(S_{c}<1\right) \& \&\left(n_{c, \text { rel }}=0\right)\right) \\
F_{C, \mathrm{act}} \cdot N_{C} \cdot r_{c, m} \cdot \operatorname{sign}\left(n_{c, \mathrm{rel}}\right) \\
\cdot\left[\mu_{C, \mathrm{sl}}+\left(\mu_{C, \mathrm{st}}-\mu_{C, \mathrm{sl}}\right) \cdot e^{\left(\left|n_{c, \mathrm{rel}}\right| C_{C} /\left(\mu_{C, \mathrm{st}}-\mu_{C, \mathrm{sl}}\right)\right)}\right] \\
\left(\left(S_{c}<1\right) \& \&\left(n_{c, \mathrm{rel}} \neq 0\right)\right) \\
0 ; \quad\left(S_{c}=1\right)
\end{array}\right.
\end{aligned}
$$

where $S_{c}=1$ is the disengagement mode, $\left(S_{c}<\right.$ $1) \& \&\left(n_{c \text {,rel }} \neq 0\right)$ is the sliding mode, $\left(S_{c}<1\right) \& \&\left(n_{c \text {,rel }}=0\right)$ is the engagement mode, $\mu_{C, s l}$ is the sliding friction coefficient of the clutch, $\mu_{C, s t}$ is the static friction coefficient of the clutch, $C_{C}$ is the friction gradient, $r_{c, m}$ is the effective friction radius, and $N_{C}$ is the number of friction surfaces.

3.5. AMT Model. Manual transmission has the highest overall efficiency and the simplest structure among all types of transmissions. AMT has a similar efficiency to manual transmission; it is essentially a manual transmission with an add-on electronic control unit that automates the gearshifting operations. There are three operation states defined in the AMT model, neutral state, speed testing state, and engaged state. Speed testing state is adopted to check the minimal time duration when the speed discrepancy is under a certain threshold that is used to avoid gear shifting frequently.

If the gear is engaged,

$$
\begin{gathered}
\omega_{I}=\omega_{I I} i_{g\left(G_{\mathrm{cur}}\right)}, \\
T_{i o}=T_{e}+T_{m 1}, \\
T_{o, \text { tran }}=T_{i o} i_{g\left(G_{\mathrm{cur}}\right)} \eta_{g\left(G_{\mathrm{cur}}\right)}+T_{m 2} i_{m 2},
\end{gathered}
$$

where $\omega_{I I}, \omega_{I}$ are the output shaft speed and the input shaft speed, $i_{g\left(G_{\text {cur }}\right)}$ is the gear ratio of current gear number, $i_{m 2}$ is the main reducer gear ratio, $T_{o \text {,tran }}$ is the torque of output shaft, and $\eta_{g\left(G_{c u r}\right)}$ is the gear efficiency.

The neutral state and speed testing state are actually the same physical state; their dynamics can be described by the following equations:

$$
\begin{gathered}
\omega_{I}(t)=\omega_{I 0}+\int_{t_{0}}^{t} \frac{T_{i o}}{J_{e}+J_{m 1}+J_{c}} d t, \\
T_{o, \text { tran }}=T_{m 2} i_{m 2},
\end{gathered}
$$

where $\omega_{I 0}$ is the speed of input shaft when gear changed from being engaged to neutral at the last time. $J_{e}, J_{m 1}$, and $J_{c}$ are the moment of inertia of engine, M1 motor, and clutch.

\subsection{Driveline and Vehicle Model. Consider}

$$
F_{\mathrm{drv}}=\frac{T_{t} i_{0} \eta-T_{\mathrm{br}}}{r_{\mathrm{wh}}}-F_{\text {loss }}
$$

where $T_{t}$ is the driving torque, $F_{\mathrm{drv}}$ is the joint force applied on vehicle, $i_{0}$ and $\eta$ are the gear ratio and efficiency of efficiency of the drivetrain. $T_{\mathrm{br}}$ is the mechanical brake torque applied on wheels, $r_{\text {wh }}$ is the wheel rolling radius, and $F_{\text {loss }}$ is the vehicle resistance described by a function of the vehicle speed, the road grade, and the other vehicle parameters, respectively [28]:

$$
F_{\text {loss }}=M g \sin \theta+\mu M g \cos \theta+0.5 \rho C_{d} A_{f} V^{2},
$$

where $M$ is the vehicle mass, $g$ is the acceleration of gravity, $\rho$ is the air density, $C_{d}$ is the coefficient of air drag, $A_{f}$ is the frontal area, $V$ is the vehicle speed, $\theta$ is the road grade, and $\mu$ is the rolling friction coefficient.

\section{Adaptive Online-Optimal Controller Design}

The equivalent consumption minimization strategy (ECMS) is the most commonly used optimization method for realtime HEV energy management. It is considered as suboptimal control method for HEV control problems. Therefore, in this study, ECMS is chosen as the online energy management strategy.

This control method can not only coordinate control of gear shifting and motor assist, but also simplify 


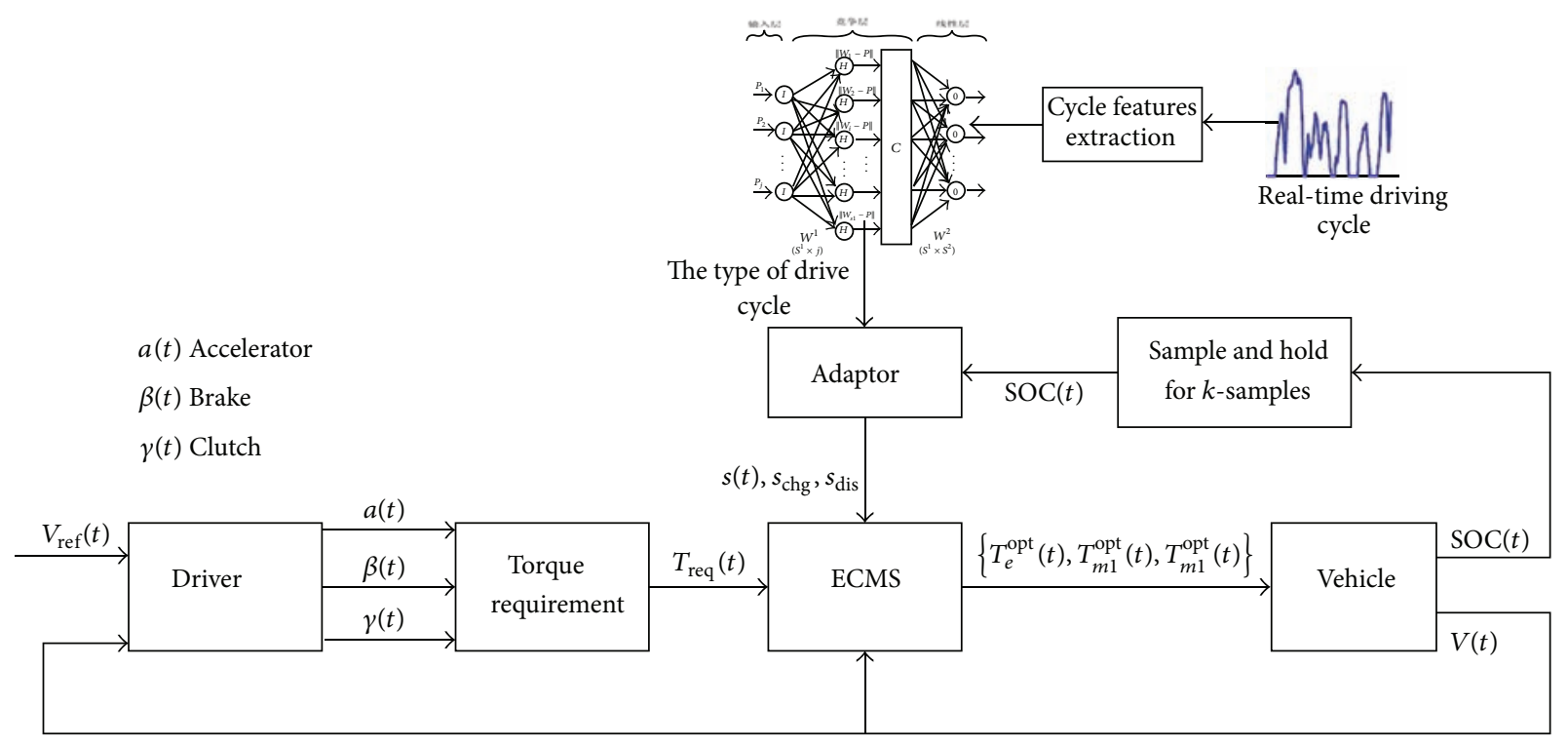

FIgURE 3: The control flowchart of adaptive ECMS (A-ECMS).

the complexity of the torque distribution in parallel mode. The optimizing searching method was adopted to obtain optimal torque distribution rules and gear-shift rules for realtime control. Nevertheless, the equivalent fuel consumption factor is one of the most important influencing factors, so a large number of scholars have conducted in-depth discussions relevant to equivalent fuel conversion factor. The control flowchart of this paper was described in Figure 3.

4.1. Equivalent Fuel Consumption Factor. Equivalent fuel consumption factor is the key for the implementation of ECMS control strategy. Because motor driving power consumed should be supplied by engine fuel consumed, the energy stored in the battery cannot be directly converted from the energy of fuel. So the fixed conversion factor or adaptive equivalent fuel consumption coefficient was proposed; the fixed conversion factor can be acquired by SAEJ1711 standards equivalent factor $(33440 \mathrm{Wh} / \mathrm{gal})$, and this method is too simple that it ignores internal resistance of the battery energy consumption, motor operating efficiency, and so on [29]. The adaptive equivalent fuel consumption coefficient calculation method has fairly ideal performance; Zhao and Stobart [30] presented minimum equivalent fuel consumption based on fuzzy control, considering the battery SOC and motor instantaneous power to acquire the real-time optimal conversion coefficient, but the computation quantity of this algorithm is still too large that it is difficult to apply in the real vehicle. In this study, a simple and accurate adaptive equivalent fuel consumption coefficient calculation method was proposed:

$$
\begin{aligned}
g_{m}= & \lambda \cdot s(t) \cdot s_{\text {dis }} \frac{P_{m}}{\bar{\eta}_{m}\left(P_{m}\right) \cdot \bar{\eta}_{\text {batt }}\left(P_{m}\right) \cdot H_{\mathrm{LHV}}} \\
& +(1-\lambda) \cdot s(t) \cdot s_{\mathrm{chg}} \cdot \bar{\eta}_{m}\left(P_{m}\right) \cdot \bar{\eta}_{\mathrm{batt}}\left(P_{m}\right) \frac{P_{m}}{H_{\mathrm{LHV}}}
\end{aligned}
$$

$$
\lambda=\frac{1+\operatorname{sign}\left(P_{m}\right)}{2},
$$

where $H_{\mathrm{LHV}}=42.6 \times 10^{3} \mathrm{~J} / \mathrm{g}$ is the diesel combustion characteristic parameters.

$\bar{\eta}_{\text {batt }}, \bar{\eta}_{m}$, respectively, are the average operating efficiency of engine and the motor under the specific drive cycle:

$$
\begin{aligned}
\bar{\eta}_{\text {batt }} & =\frac{\sum_{j=1}^{k}\left(\eta_{\text {batt }}(j) \cdot P_{m}(j)\right)}{\sum_{j=1}^{k} P_{m}(j)}, \\
\bar{\eta}_{m} & =\frac{\sum_{j=1}^{k}\left(\eta_{m}(j) \cdot P_{m}(j)\right)}{\sum_{j=1}^{k} P_{m}(j)},
\end{aligned}
$$

where $K$ is the number of sampling points and $\eta_{m}, \eta_{\text {batt }}, P_{m}$, and $P_{\text {batt }}$ are the motor efficiency, battery efficiency, motor power, and battery power, respectively.

Battery SOC equivalent conversion factors are

$$
s(t)=s_{0}+K_{p} \cdot\left(\mathrm{SOC}_{\mathrm{obj}}-\operatorname{SOC}(t)\right) .
$$

Target battery $\mathrm{SOC}_{\mathrm{obj}}=0.6 s_{0}, K_{p}$ adjusts the parameter, $s_{0}=1$, and $K_{p}=1.82$.

$s_{\text {chg }}, s_{\text {dis }}$ are the equivalent charge and discharge coefficients.

4.2. Objective Function. The energy management controller aims to obtain minimum fuel consumption by coordinated 


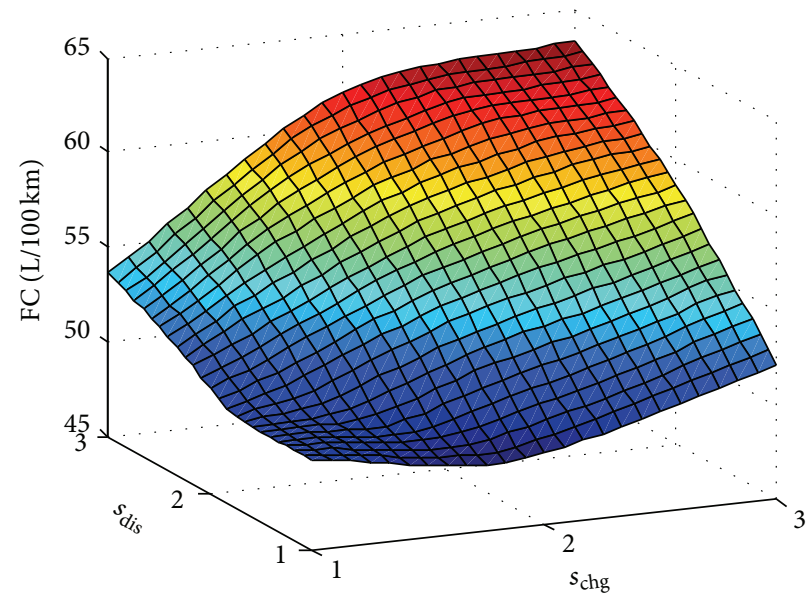

(a) CYC_NewYorkBus

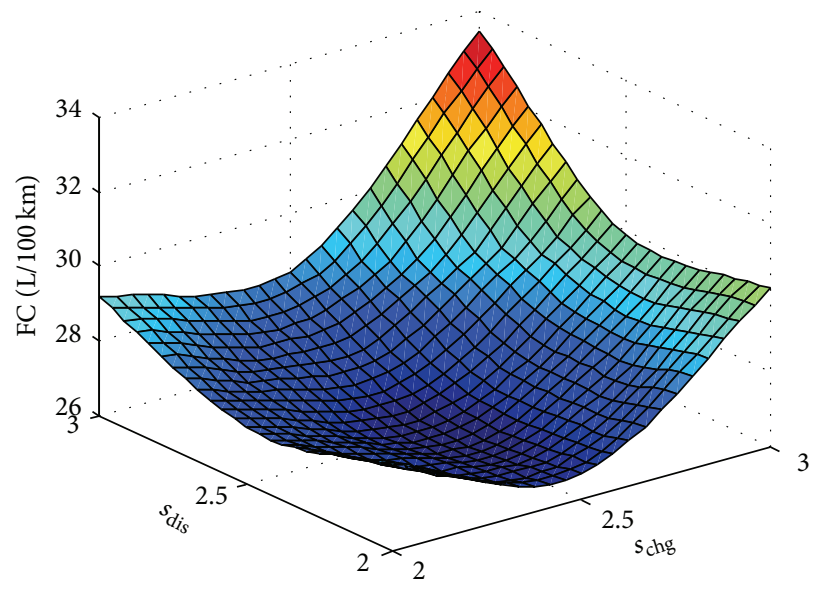

(c) CYC_INDIA_URBAN_SAMPLE

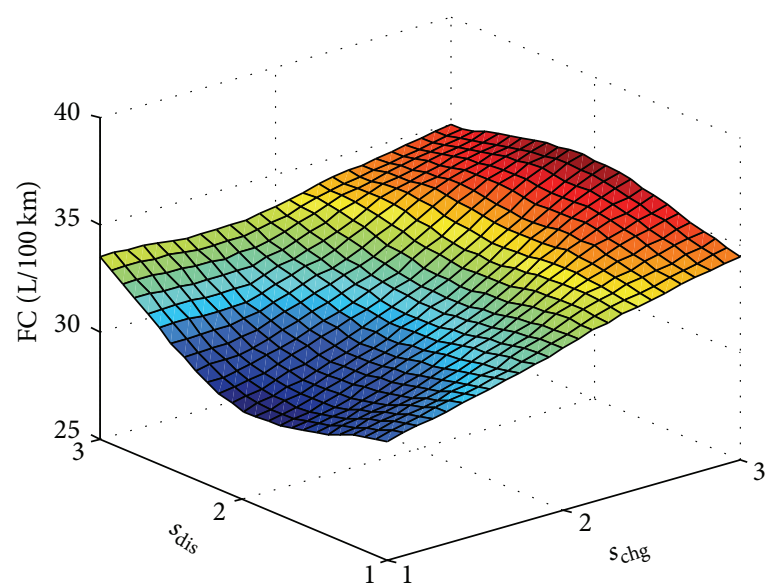

(b) CYC_NurembergR36

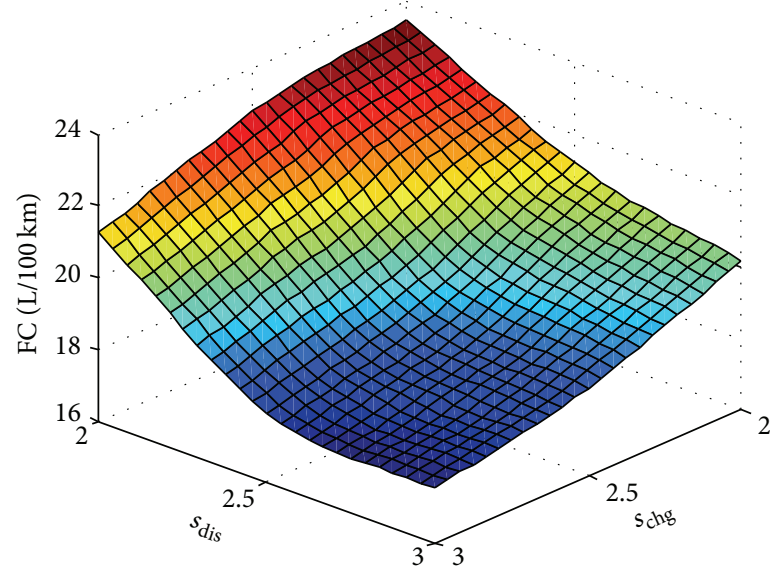

(d) CYC_SC03

FiguRE 4: Equivalent charge and discharge coefficients with fuel economy.

control of engine power, M1 motor power, M2 motor power, and transmission speed position:

$$
\begin{gathered}
J=g_{e}+g_{m 1}+g_{m 2}, \\
\left\{P_{e}^{\mathrm{opt}}(t), P_{m 1}^{\mathrm{opt}}(t), P_{m 2}^{\mathrm{opt}}(t), G_{\mathrm{ear}}^{\mathrm{opt}}\right\} \\
=\arg \min _{\left\{P_{e}(t), P_{m 1}(t), P_{m 2}(t)\right\}} J\left(P_{\text {req }}(t) \geq 0\right),
\end{gathered}
$$

where $g_{e}$ is the engine instantaneous fuel consumption, $g_{m 1}$ is the M1 motor equivalent instantaneous fuel consumption, $g_{m 2}$ is the M2 motor equivalent instantaneous fuel consumption, $P_{e}^{\text {opt }}$ is the optimal engine power output, $P_{m 1}^{\mathrm{opt}}$ is the optimal M1 motor power output, $P_{m 2}^{\text {opt }}$ is the optimal M2 motor power output, $G_{\text {ear }}^{\text {opt }}$ is the optimal gear, and $P_{\text {req }}$ is the power requirement.
4.3. Constraints. In order to extend the battery life and maximum use of charge and discharge power in the reasonable range, they need to limit battery SOC within a certain range:

$$
\begin{gathered}
P_{\text {req }}(t)=P_{e}(t)+P_{m 1}(t)+P_{m 2}(t), \\
\operatorname{SOC}_{\text {min }}<\mathrm{SOC}(t)<\mathrm{SOC}_{\text {max }}, \\
0 \leq P_{e}(t) \leq P_{e_{-} \text {max }}(t), \\
P_{m 1_{-} \text {min }}(t) \leq P_{m 1}(t) \leq P_{m 1_{\text {_max }}}(t), \\
P_{m 2_{\text {_min }}}(t) \leq P_{m 2}(t) \leq P_{m 2_{\text {_max }}}(t) .
\end{gathered}
$$

4.4. Adaptive Equivalent Charge and Discharge Coefficients. According to the simulation results demonstrate that different drive cycles correspond to different optimal equivalent charge and discharge coefficients. By choosing different charge and discharge coefficients to simulate calculation, 
TABLE 3: Typical driving cycle optimal coefficients.

\begin{tabular}{lll}
\hline Typical driving cycle & $S_{\text {chg }}$ & $S_{\text {dis }}$ \\
\hline CYC_NewYorkBus & 2.25 & 2.13 \\
CYC_NurembergR36 & 2.39 & 2.19 \\
CYC_INDIA_URBAN_SAMPLE & 2.74 & 2.45 \\
CYC_SC03 & 2.92 & 2.67 \\
\hline
\end{tabular}

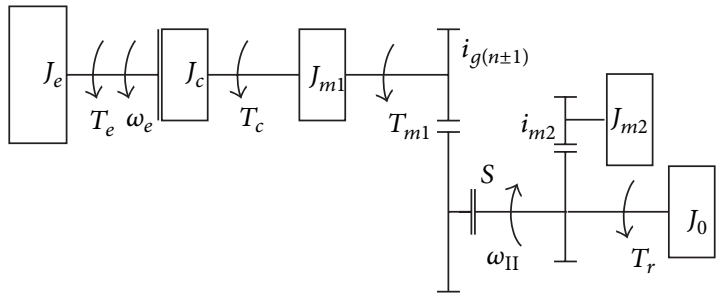

FIgURE 5: Vehicle dynamics model.

the curved surface fitting shows that choosing a smaller equivalent coefficient means that electric drive is more energy efficient in the low speed. In the high way, selecting a larger equivalent coefficient is more efficient.

From Figure 4 fitting surfaces, you can get the lowest fuel consumption with different charge and discharge coefficient under each drive cycle, the optimal charge and discharge coefficients were shown in Table 3 . Then, selecting optimal charge and discharge coefficient based on the drive cycle recognition result to select optimal charge and discharge coefficient. Driving cycle recognition algorithm is based on the learning vector quantization neural network, through selecting the best identification parameters, the optimal identification cycle, and forecast period to identify the closest types of drive cycle $[31,32]$.

\section{Analytical Solution to the Minimization Problem}

5.1. Gear-Shifting Rules Based on the Minimum Equivalent Fuel Consumption. The simplified physical model of Figure 5 was presented for the analysis of powertrain system. According to the mathematical model of vehicle drive system, the establishment of kinetic equations unified a formula as follows:

$$
\left(J_{e}+J_{c}+J_{m 1}+\frac{J_{m 2} i_{m 2}^{2}+J_{o}}{i_{g(n)}^{2}}\right) \dot{\omega}_{e}=T_{e}+T_{m 1}+\frac{T_{m 2} i_{m 2}-T_{r}}{i_{g(n)}},
$$

where $J_{m 1}$ is the equivalent moment of inertia of M1 motor, $J_{m 2}$ is the equivalent moment of inertia of M2 motor, $J_{e}$ is the equivalent moment of inertia of engine, $J_{c}$ is the equivalent moment of inertia of clutch, $J_{o}$ is the equivalent moment of inertia of the wheels and vehicle, and $i_{m 2}$ is the torque coupler transmission ratio.

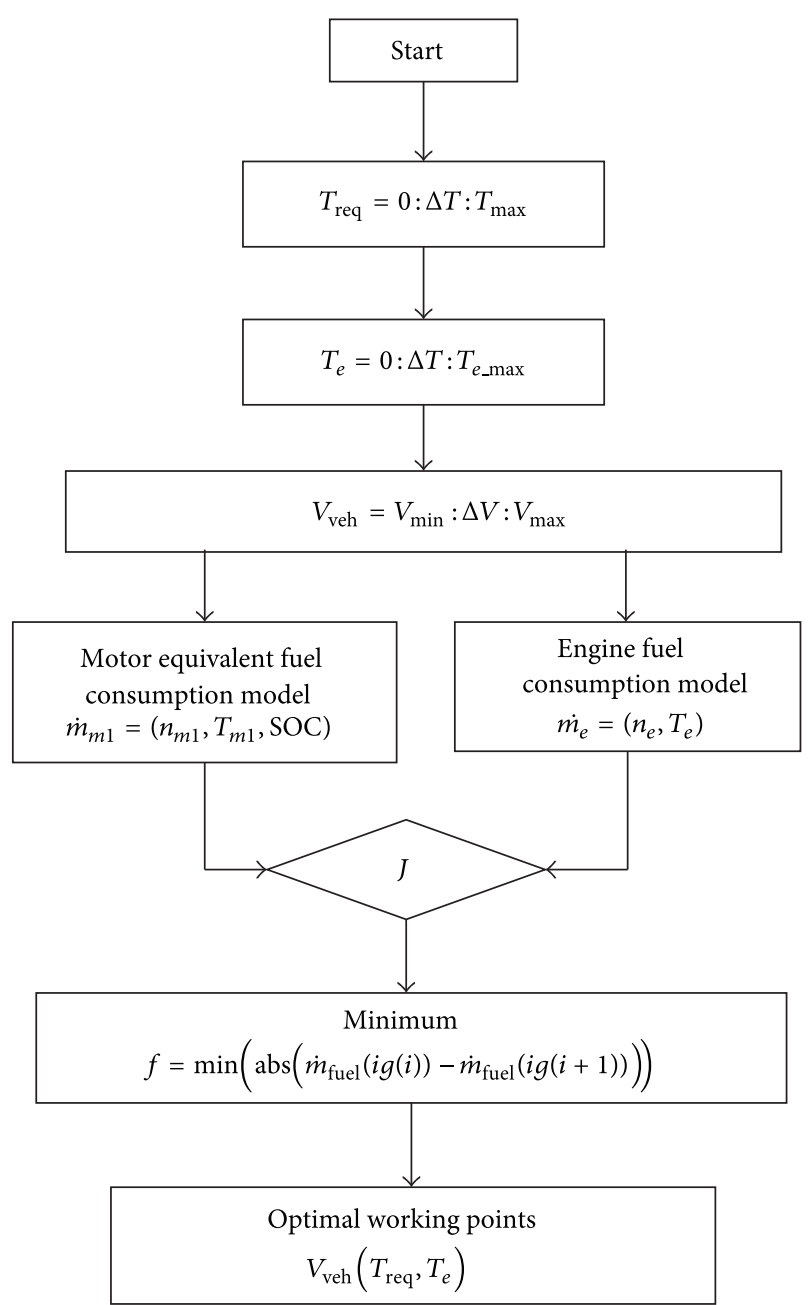

FIGURE 6: The flowchart of gear-shift rules optimization computation.
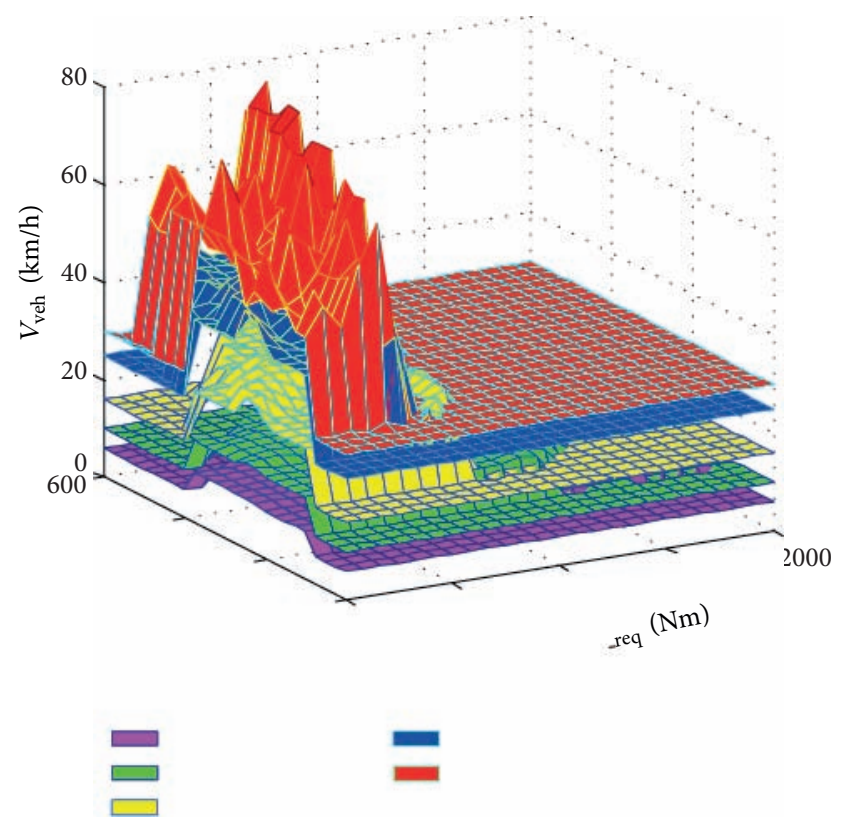

FIGURE 7: Up-shift surfaces at the $80 \%$ of battery SOC. 


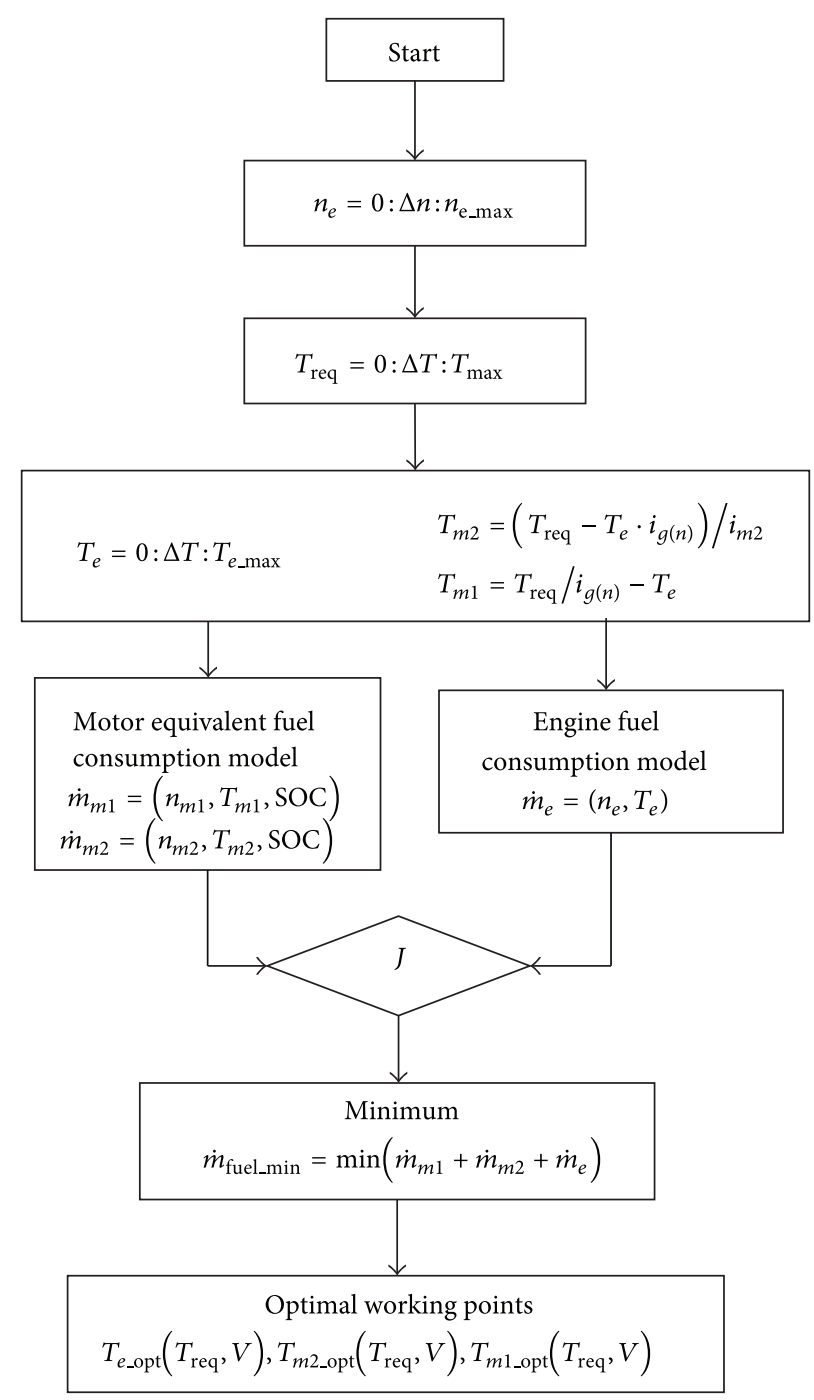

FIGURE 8: The flowchart of instantaneous optimal torque distribution.

To get the lowest fuel consumption by searching for the optimal torque distribution and gear-shifting rules, we need to simplify the dynamic model:

$$
\begin{gathered}
\left(T_{e}+T_{m 1}\right) \cdot i_{g(n)}=T_{r}-T_{m 2} i_{m 2}, \\
\frac{\omega_{e}}{i_{g(n)}}=\frac{\omega_{m 1}}{i_{g(n)}}=\frac{\omega_{m 2}}{i_{m 2}},
\end{gathered}
$$

where $\omega_{m 1}$ is the M1 motor speed, $\omega_{m 2}$ is the M2 motor speed, and $i_{g(n)}$ is the transmission gear ratio.

The flowchart of gear-shift rules optimization computation was shown in Figure 6, through the mesh generation of engine torque and torque requirement to search for the optimal shift points and fit these points into shift surfaces and then to code into the controller and optimize the efficiency of the engine and the motor.
Figure 7 represents up-shift surface from 1st gear to 2nd gear, 2 nd gear to 3 rd gear, and so on at the $80 \%$ of battery SOC:

$$
T_{\text {equ_req }}=T_{\text {req }}-T_{m 2} \cdot i_{m 2} \cdot
$$

Down-shift rules were to ensure the less frequent gear shifting, but they would cause high fuel consumption (FC). Most of them choose a reasonable negative offset velocity to make a compromise.

5.2. Energy Management Control Strategy Based on the Minimum Equivalent Fuel Consumption. This series-parallel drive system included parallel mode 1 (engine and M2 motor) in the low speed and parallel mode 2 (engine and M1 motor) in the high speed, by searching for the best torque allocation rules into the real-time controller. Control strategy will no longer distinguish electric, pure engine-driven, and parallel mode, but through the use of three-dimensional 


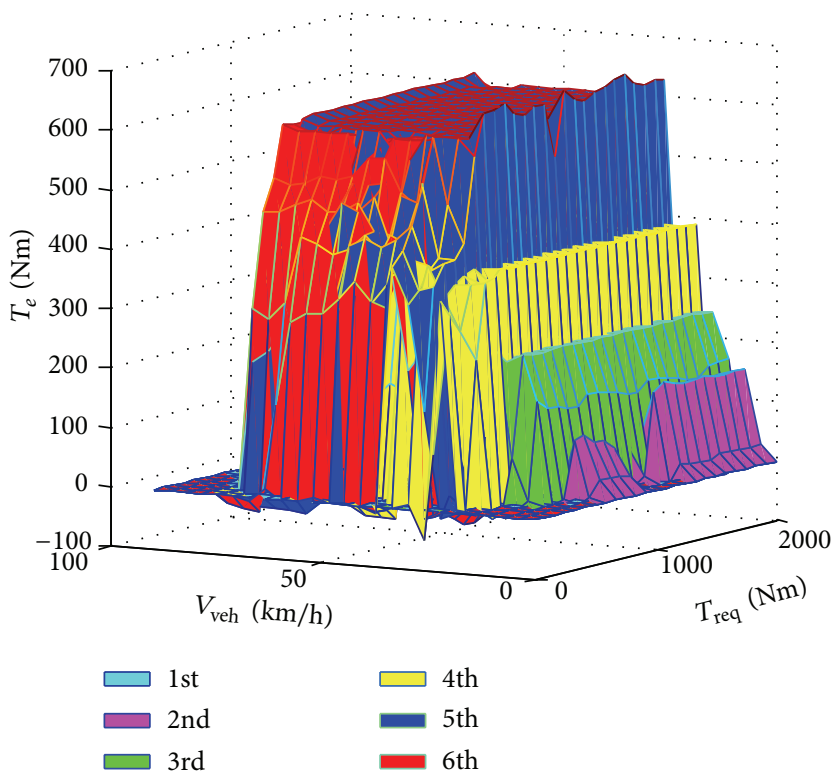

Figure 9: Parallel mode 1 at the $80 \%$ of battery SOC.

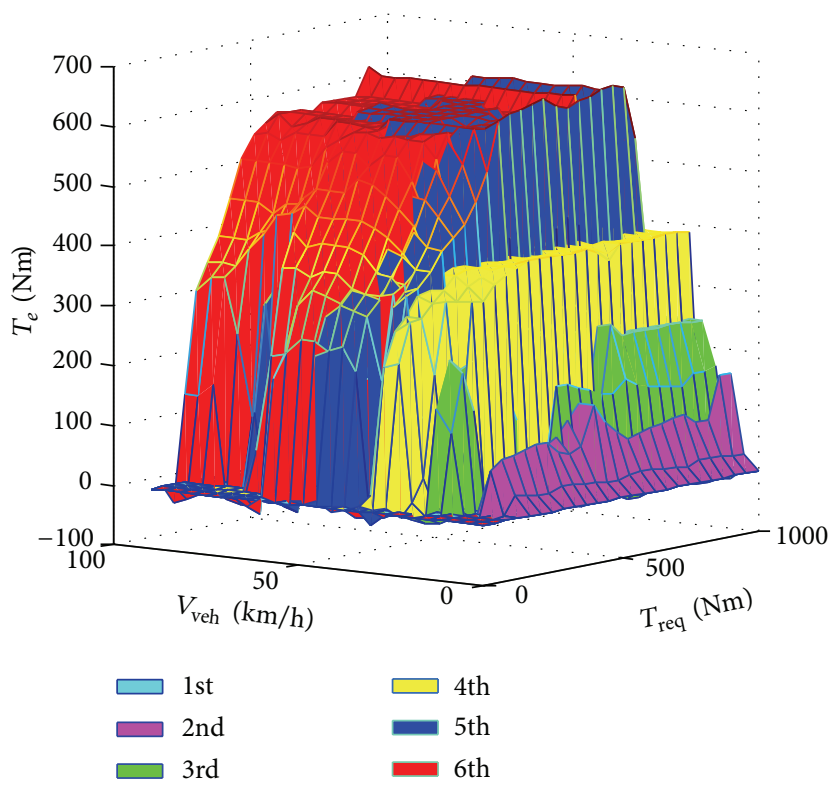

Figure 10: Parallel mode 2 at the $80 \%$ of battery SOC.

interpolation method to distribute engine torque and electric motor torque. This strategy not only can avoid the complexity of the drive mode and optimize torque distribution, but also can solve the problem of tedious debugging to achieve good simulation results.

The flowchart of instantaneous optimal torque distribution was shown in Figure 8, through the mesh generation of engine torque, engine speed, and torque requirement to search for the optimal torque distribution. Figure 8 proposed the offline optimal torque distribution in the specific drive cycle and then extracted the offline optimal control rules into the real-time controller.
The battery SOC is divided into many different threshold values, which corresponds with the different equivalent fuel consumption coefficients to repetitive computation. Figures 9 and 10 show the optimal engine torques in the different gear at the $80 \%$ of battery SOC.

\section{Simulation and Experiments Validation}

HIL simulation is helpful to verify the real time of control strategy and reduce the vehicle debug cycle by verifying that CAN bus communication works well in the hardware-in-loop 


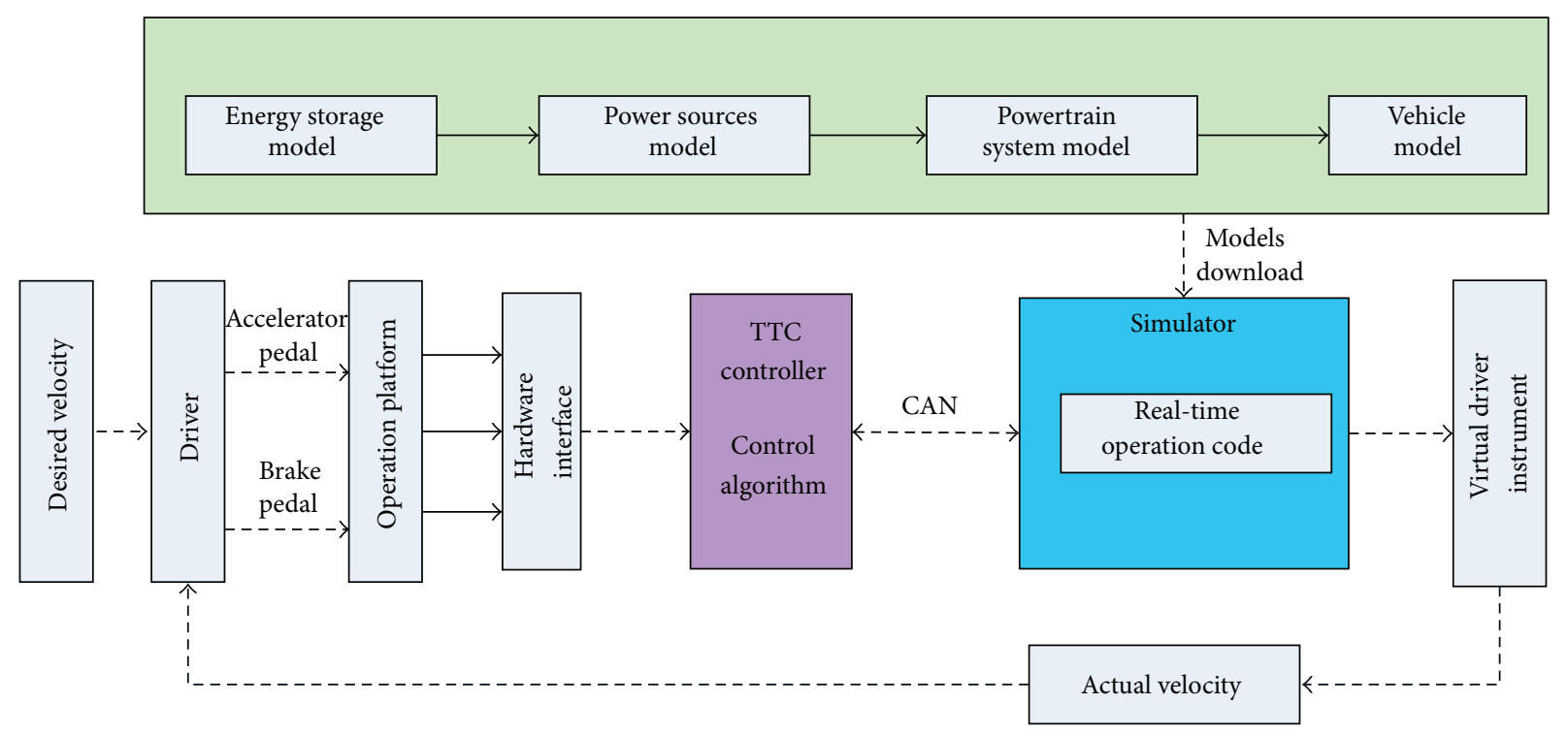

FIGURE 11: Hardware in loop real-time simulation architecture.

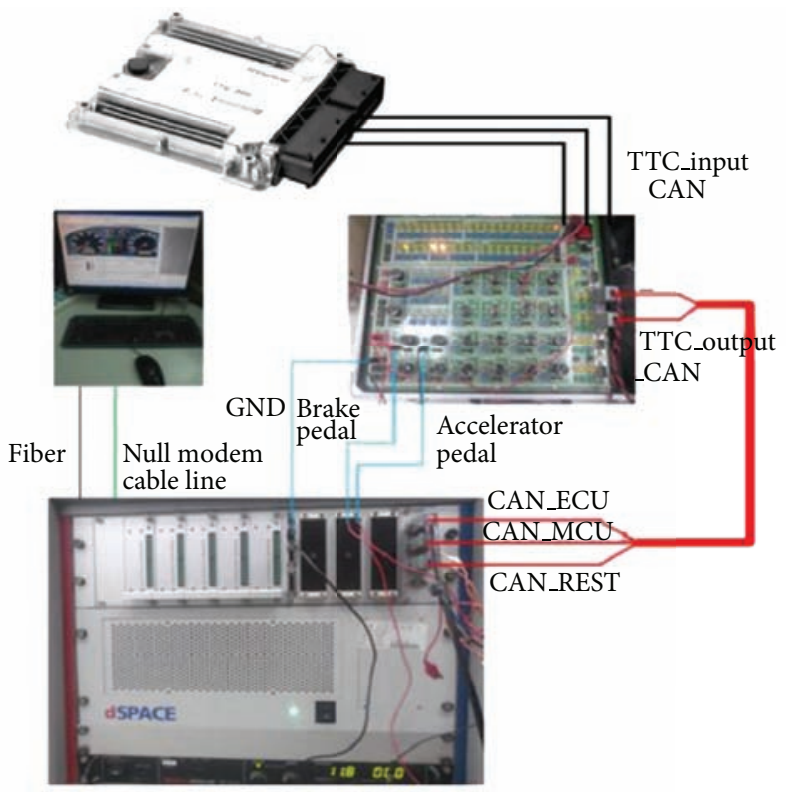

FIGURE 12: Simulator test bench for the HCU of the hybrid bus.

system. In this research, dSPACE/simulator was selected as HIL simulator for its high real-time performance and high simulation precision. The HEV powertrain model was developed and then vehicle model was coded and downloaded into simulator. TTC controller was chosen as the hybrid vehicle controller unit (HCU) and then control algorithm was compiled and downloaded into TTC controller by automatic code generation techniques [33]. Realizing the real-time communication between the virtual vehicle simulator and the real HCU is via CAN messages and analog signals. Simulator test bench was displayed in Figure 12.

In order to maintain the high-fidelity virtual model in the hardware-in-the-loop simulation system and to simulate the real vehicle test. The HIL simulation model should make a compromise on real-time requirements and complexity of the model. In this study, The HEV real-time simulation model includes hybrid vehicle powertrain components, driving environment, and driver. The HEV control strategy model includes torque requirements, torque distribution, torque coordinating, and gear-shifting controlling. Real-time simulation architecture was presented in Figure 11.

Figure 13(a) is the China urban driving cycle; Figure 13(b) shows that the charge and discharge coefficients are updated in real time by drive cycle recognition algorithm to ensure the suboptimal torque distribution and suboptimal gear-shifting rules. In Figure 13(d), the control strategy can ensure that the 


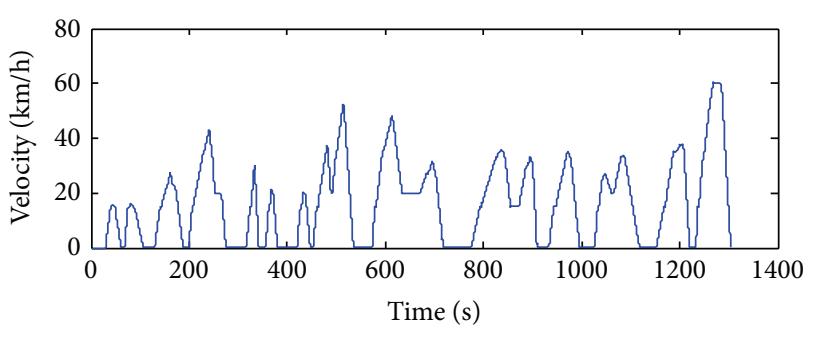

(a) China urban driving cycle

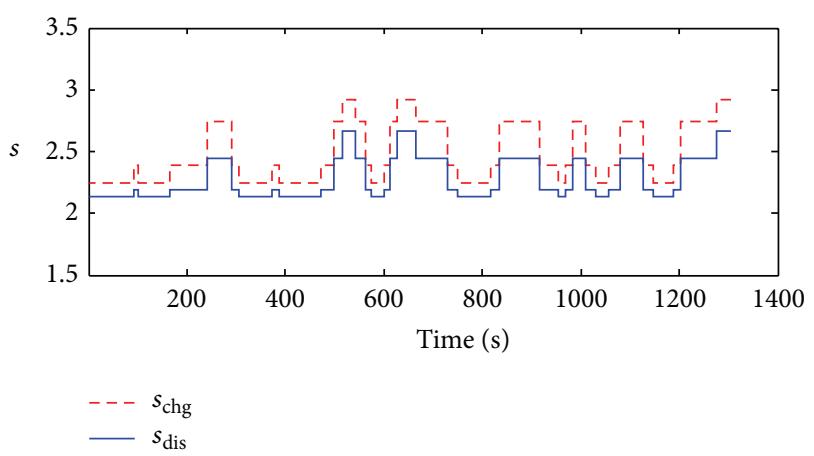

(b) Equivalent charge and discharge coefficient

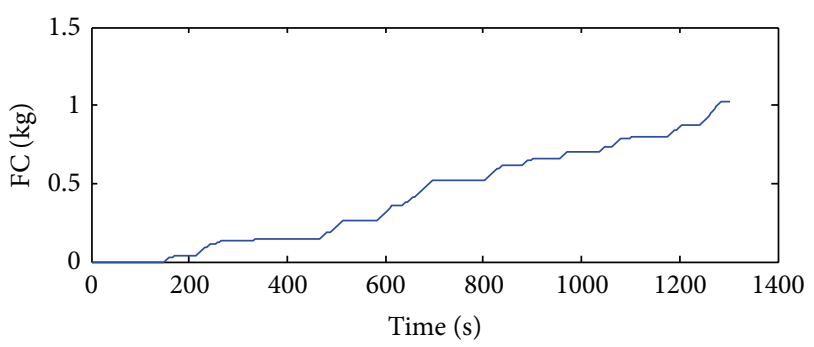

(c) Fuel consumption

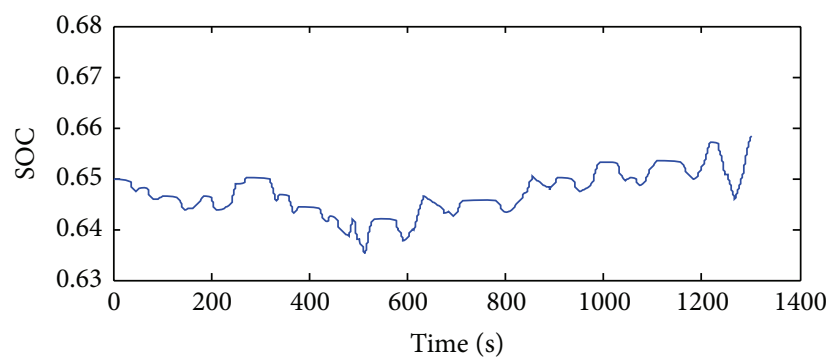

(d) Battery SOC

FIgURE 13: Simulation results of HEB based on the A-ECMS.

battery operates within the upper and lower bounds and can sustain the battery SOC over the China urban driving cycle while minimizing fuel consumption.

The distribution maps for the operating points of the engine, M1 motor, and M2 motor are in Figure 14, which demonstrate that the hybrid bus can be driven in pure electric mode during low-speed driving, in parallel mode 1 during low-speed and accelerating driving, and in parallel mode 2 during high speed under the real-time A-ECMS controller above. Furthermore, the engine can avoid operating in the idle region. The M2 motor in the hybrid bus should propel the vehicle during low-speed driving and absorb regenerative
TABLE 4: Fuel consumption in the China urban driving cycle.

\begin{tabular}{lcc}
\hline Control strategy & $\begin{array}{c}\text { Fuel consumption } \\
(\mathrm{L} / 100 \mathrm{~km})\end{array}$ & Improvement (\%) \\
\hline Conventional & 38.92 & - \\
Logic threshold & 26.51 & 31.89 \\
A-ECMS & 23.13 & 40.57 \\
\hline
\end{tabular}

energy during braking. It can also be used to regulate the peak and valley load of the engine through power assist and electricity generation. The M1 motor in the hybrid bus should propel the vehicle during high-speed driving and regulate the engine operating points as well, so that most of the operating points of the engine can be moved to the high-efficiency region. Consequently, the fuel consumption of the hybrid bus can be significantly reduced.

Table 4 gives the fuel consumption simulation results for the hybrid bus with different control strategies based on the same prototype vehicle. As is shown in Table 4, hybrid bus using the proposed real-time A-ECMS control strategy can achieve $12.75 \%$ and $40.57 \%$ lower fuel consumption compared to the hybrid bus employing the logicthreshold control strategy and the conventional ICE bus, respectively.

In Figure 15, we can get that the different initial SOC value is in accordance with the fuel economy. The battery acts as a buffer for load balancing and different battery SOC values will lead to different energy losses for the different battery internal resistances. The fuel economy is $23.13 \mathrm{~L}$ and $22.82 \mathrm{~L}$ per $100 \mathrm{~km}$ at the initial SOC value of 0.6 and 0.7 , respectively, that are better performance than $24.62 \mathrm{~L}$ per $100 \mathrm{~km}$ at the initial SOC value of 0.5 .

\section{Conclusion}

A real-time ECMS was developed for a series-parallel hybrid electric bus, and a HIL simulation system was constructed for energy management strategy investigation and verification in this study. The EMS design goal is minimizing fuel consumption while meeting drivability requirements and sustaining the battery SOC level; the A-ECMS was proposed to coordinate the relationship between the gear shifting and motor assist. At the same time, in order to realize adaptive control under different drive cycles, drive cycle recognition was presented to update the charge and discharge coefficients so as to achieve better fuel economy in each drive cycle.

The HIL simulation results demonstrated that the fuel consumption of the hybrid bus with real-time A-ECMS control strategy can be reduced by $12.75 \%$ and $40.57 \%$ compared to the hybrid electric bus with the logic-threshold control strategy and the conventional ICE bus, respectively.

The real-time optimization control strategy plays an important role in the vehicle fuel economy improvement; the successful application of A-ECMS control strategy in the series-parallel hybrid electric bus provides good support for the vehicle experiment. In the next step in our work, we will have a trial that implements the proposed A-ECMS control strategy in a real controller with a real-world application. 


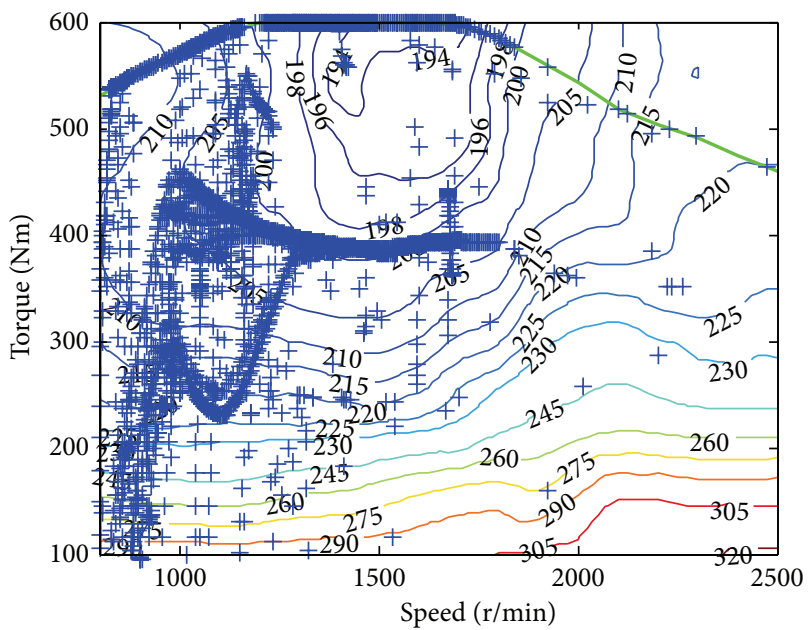

(a) Engine operating points distribution

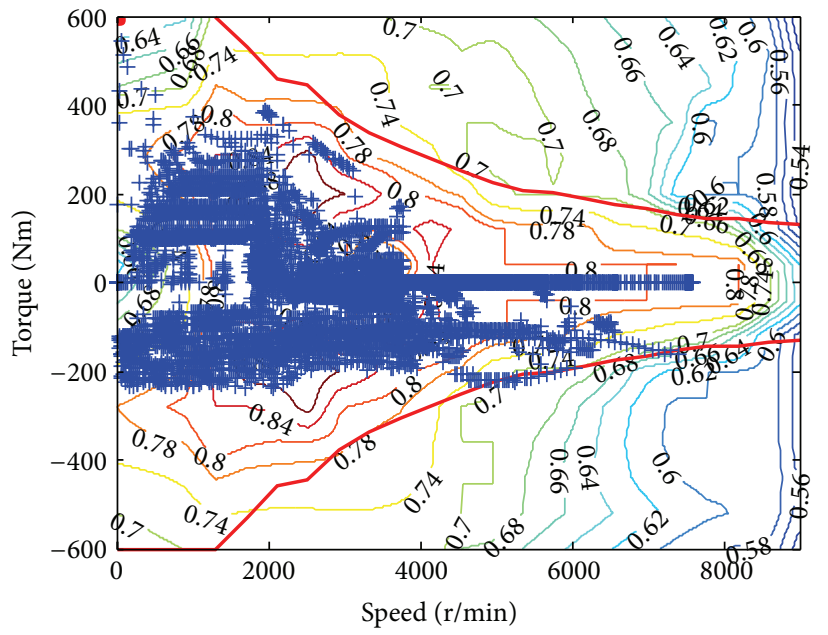

(b) M2 motor operating points distribution

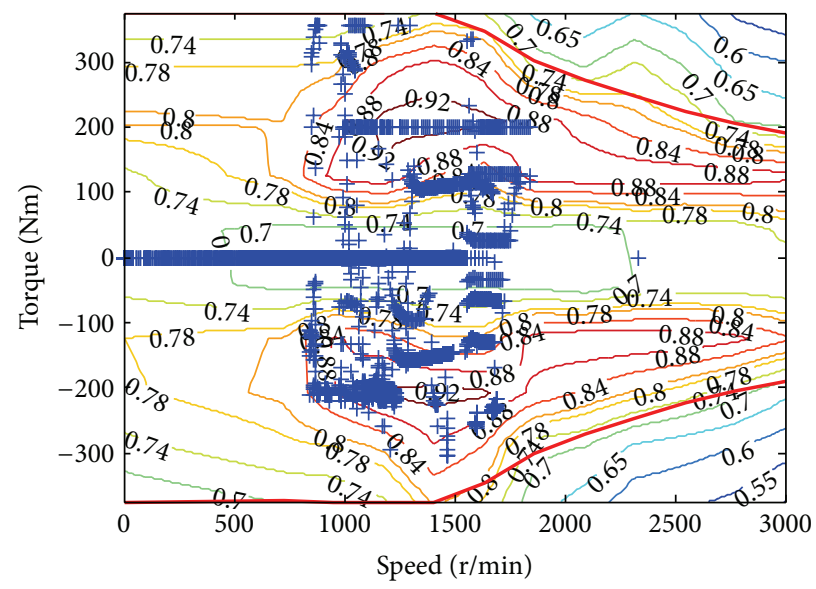

(c) M1 motor operating points distribution

FIGURE 14: Power source operating points distribution.

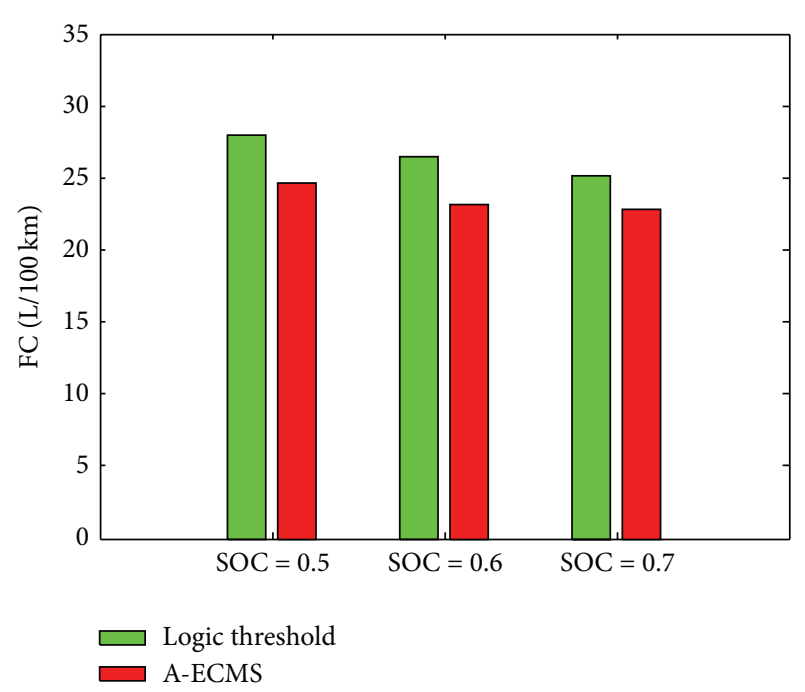

Figure 15: Fuel consumption under different initial SOC.

\section{Nomenclature}

ECMS: Equivalent consumption minimization strategy

EMS: Energy management strategy

HEV: Hybrid electric vehicle

DP: Dynamic programming

SDP: Stochastic dynamic programming

PMP: Pontryagin minimum principle

HIL: Hardware-in-the-loop

ECU: Electronic control unit

HCU: Hybrid vehicle controller unit

HEB: Hybrid electric bus

AMT: Automated mechanical transmission

SOC: State of charge

TCU: Transmission control unit

BSFC: Brake specific fuel consumption

PNGV: Partnership for a New Generation of Vehicles 


\section{A-ECMS: Adaptive equivalent consumption minimization strategy \\ CAN: Controller area network.}

\section{Conflict of Interests}

The authors declare that there is no conflict of interests regarding the publication of this paper.

\section{Acknowledgments}

The authors would like to thank the School of Automotive Engineering, Changchun, Jilin, China, as well as the National Natural Science Foundation of China for their supports on this project (Grant no. 51075179) and the National High Technology Research and Development Program of China (863 Program) for their supports on this project (Grant no. 2011AA11A210).

\section{References}

[1] S. B. Han, Y. H. Chang, E. Y. Lee, Y. J. Chung, and B. Suh, "Emissions simulation in a $7000 \mathrm{~kg}$-grade diesel hybrid electric vehicle," International Journal of Automotive Technology, vol. 11, no. 1, pp. 105-110, 2010.

[2] A. Boukehili, Y. T. Zhang, Q. Zhao, C. Q. Ni, H. F. Su, and G. J. Huang, "Hybrid vehicle power management modeling and refinement," International Journal of Automotive Technology, vol. 13, no. 6, pp. 987-998, 2012.

[3] S. Bogosyan, M. Gokasan, and D. J. Goering, "A novel model validation and estimation approach for hybrid serial electric vehicles," IEEE Transactions on Vehicular Technology, vol. 56, no. 4, pp. 1485-1497, 2007.

[4] W. Haikun, F. Lixin, Z. Yu, and L. He, "Modelling of the fuel consumption for passenger cars regarding driving characteristics," Transportation Research D, vol. 13, pp. 479-482, 2008.

[5] A. Rousseau, S. Saglini, M. Jakov, D. Gray, and K. Hardy, “Tradeoffs between fuel economy and NOx emissions using fuzzy logic control with a hybrid CVT configuration," International Journal of Automotive Technology, vol. 4, no. 1, pp. 47-55, 2003.

[6] B.-C. Chen, Y.-Y. Wu, Y.-L. Wu, and C.-C. Lin, "Adaptive power split control for a hybrid electric scooter," IEEE Transactions on Vehicular Technology, vol. 60, no. 4, pp. 1430-1437, 2011.

[7] O. Dingel, N. Pini, I. Trivic et al., "Benchmarking Hybrid Concepts: On-Line versus Off-Line Fuel Economy Optimization for Different Hybrid Architectures," SAE Technical Paper 2013-240084, 2013.

[8] K. L. Butler, M. Ehsani, and P. Kamath, "A matlab-based modeling and simulation package for electric and hybrid electric vehicle design," IEEE Transactions on Vehicular Technology, vol. 48, no. 6, pp. 1770-1778, 1999.

[9] S. Delprat, J. Lauber, T. M. Guerra, and J. Rimaux, "Control of a parallel hybrid powertrain: optimal control," IEEE Transactions on Vehicular Technology, vol. 53, no. 3, pp. 872-881, 2004.

[10] K. Chen, A. Bouscayrol, A. Berthon, P. Delarue, D. Hissel, and R. Trigui, "Global modeling of dfferent vehicles," IEEE Vehicular Technology Magazine, vol. 4, no. 2, pp. 80-89, 2009.

[11] V. T. Minh and A. A. Rashid, "Automatic control of clutches and simulations for parallel hybrid vehicles," International Journal of Automotive Technology, vol. 13, no. 4, pp. 645-651, 2012.
[12] G. Paganelli, S. Delprat, T. M. Guerra, J. Rimaux, and J. J. Santin, "Equivalent consumption minimization strategy for parallel hybrid powertrains," in Proceedings of the 55th Vehicular Technology Conference, pp. 2076-2081, May 2002.

[13] G. Paganelli, S. Delprat, T. Guerra et al., "Equivalent consumption minimization strategy for parallel hybrid powertrains," in Proceedings of the IEEE Vehicular Technlogy Conference, pp. 2076-2081, 2002.

[14] B. Geng, J. K. Mills, and D. Sun, "Energy management control of microturbine-powered plug-in hybrid electric vehicles using the telemetry equivalent consumption minimization strategy," IEEE Transactions on Vehicular Technology, vol. 60, no. 9, pp. 4238-4248, 2011.

[15] O. Dingel, N. Pini, I. Trivic et al., "Benchmarking Hybrid Concepts: On-Line versus Off-Line Fuel Economy Optimization for Different Hybrid Architectures," SAE Technical Paper 2013-240084.

[16] J.-P. Gao, G.-M. G. Zhu, E. G. Strangas, and F.-C. Sun, "Equivalent fuel consumption optimal control of a series hybrid electric vehicle," Proceedings of the Institution of Mechanical Engineers D, vol. 223, no. 8, pp. 1003-1018, 2009.

[17] C. Musardo, G. Rizzoni, Y. Guezennec, and B. Staccia, "AECMS: an adaptive algorithm for hybrid electric vehicle energy management," European Journal of Control, vol. 11, no. 4-5, pp. 509-524, 2005.

[18] X. Ye, Z. Jin, X. Hu, Y. Li, and Q. Lu, "modeling and control strategy development of a parallel hybrid electric bus," International Journal of Automotive Technology, vol. 14, no. 6, pp. 971985, 2013.

[19] V. Sezer, M. Gokasan, and S. Bogosyan, "A novel ECMS and combined cost map approach for high-efficiency series hybrid electric vehicles," IEEE Transactions on Vehicular Technology, vol. 60, no. 8, pp. 3557-3570, 2011.

[20] M. Sivertsson, "Adaptive control using map-based ECMS for a PHEV," in Proceedings of the IFAC Workshop on Engine and Powertrain Control, Simulation and Modeling (ECOSM' 12), pp. 357-362, 2012.

[21] R. Chen, L. Mi, and W. Tan, "A new hardware-in-the-loop test system for electronic control unit of dual-clutch transmission vehicle," Advanced Materials Research, vol. 490-495, pp. 13-18, 2012.

[22] S. Onori, L. Serrao, and G. Rizzoni, "Adaptive equivalent consumption minimization strategy for hybrid electric vehicles," in Proceedings of the Dynamic Systems and Control Conference (DSCC '10), pp. 499-505, September 2010.

[23] H.-W. He, R. Xiong, and Y.-H. Chang, "Dynamic modeling and simulation on a hybrid power system for electric vehicle applications," Energies, vol. 3, no. 11, pp. 1821-1830, 2010.

[24] G. Rizzoni, L. Guzzella, and B. M. Baumann, "Unified modeling of hybrid electric vehicle drivetrains," IEEE/ASME Transactions on Mechatronics, vol. 4, no. 3, pp. 246-257, 1999.

[25] V. H. Johnson, "Battery performance models in ADVISOR," Journal of Power Sources, vol. 110, no. 2, pp. 321-329, 2002.

[26] P. Nelson, I. Bloom, K. Amine, and G. Henriksen, "Design modeling of lithium-ion battery performance," Journal of Power Sources, vol. 110, no. 1, pp. 437-444, 2002.

[27] L. Wang, Y. Zhang, C. Yin, H. Zhang, and C. Wang, "Hardwarein-the-loop simulation for the design and verification of the control system of a series-parallel hybrid electric city-bus," Simulation Modelling Practice and Theory, vol. 25, pp. 148-162, 2012. 
[28] M. Ehsani, K. M. Rahman, and H. A. Toliyat, "Propulsion system design of electric and hybrid vehicles," IEEE Transactions on Industrial Electronics, vol. 44, no. 1, pp. 19-27, 1997.

[29] O. Simona, S. Lorenzo, and R. Giorgio, "Adaptive equivalent consumption minimization strategy for hybrid electric vehicles," in Proceedings of the ASME Dynamic Systems and Control Conference, pp. 499-505, 2010.

[30] D. Zhao and R. Stobart, "Real-Time Optimal Energy Management of Heavy Duty Hybrid electric Vehicles," SAE Technical Paper 2013-01-1748.

[31] C.-C. Lin, S. Jeon, H. Peng, and J. M. Lee, "Driving pattern recognition for control of hybrid electric trucks," Vehicle System Dynamics, vol. 42, no. 1-2, pp. 41-58, 2004.

[32] R. Langari and J.-S. Won, "Intelligent energy management agent for a parallel hybrid vehicle. Part I: system architecture and design of the driving situation identification process," IEEE Transactions on Vehicular Technology, vol. 54, no. 3, pp. 925934, 2005.

[33] J. Wu, C. Dufour, and L. Sun, "Hardware-in-the-loop testing of hybrid vehicle motor drives at Ford Motor Company," in Proceedings IEEE Vehicle Power and Propulsion Conference (VPPC '10), September 2010. 


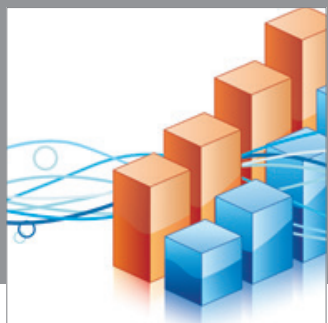

Advances in

Operations Research

mansans

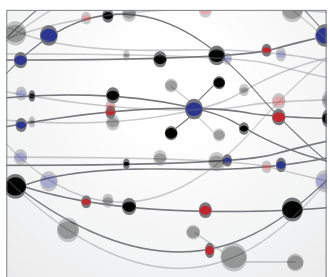

The Scientific World Journal
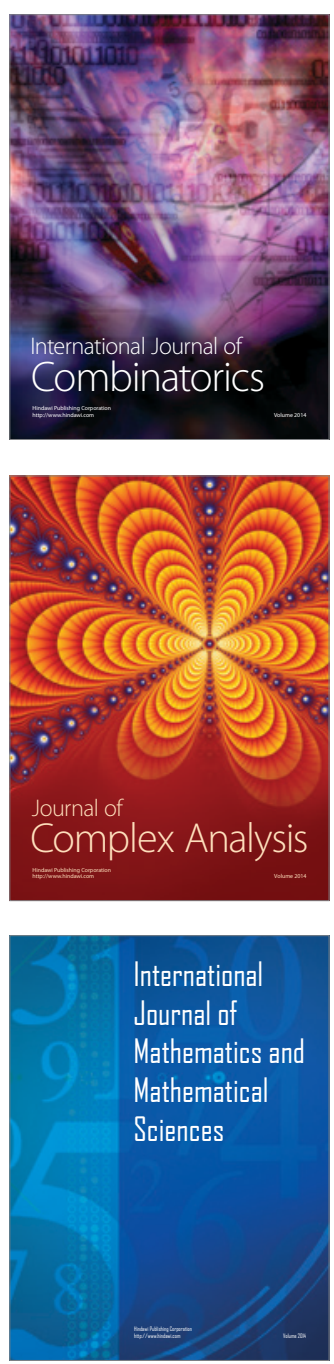
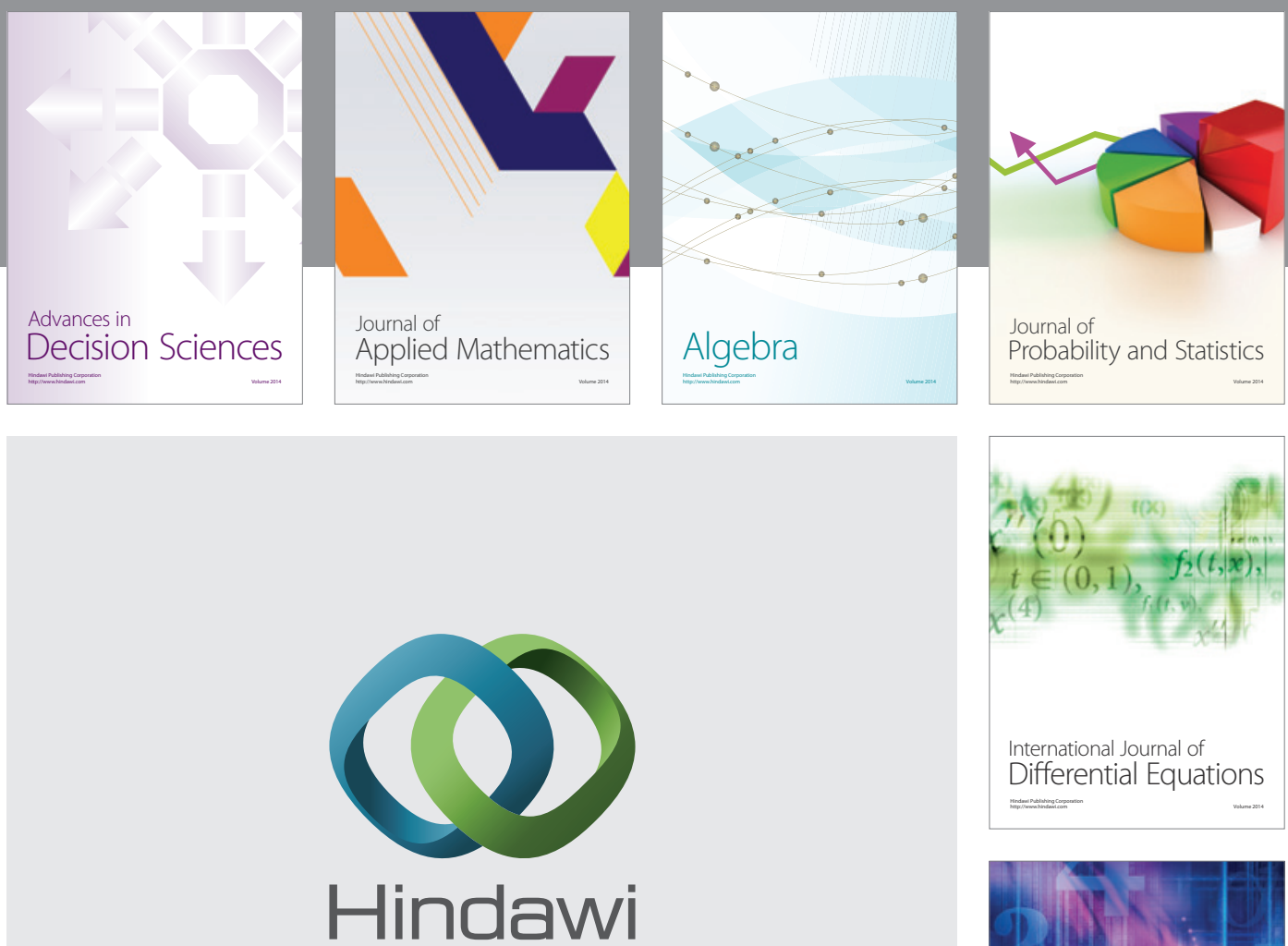

Submit your manuscripts at http://www.hindawi.com
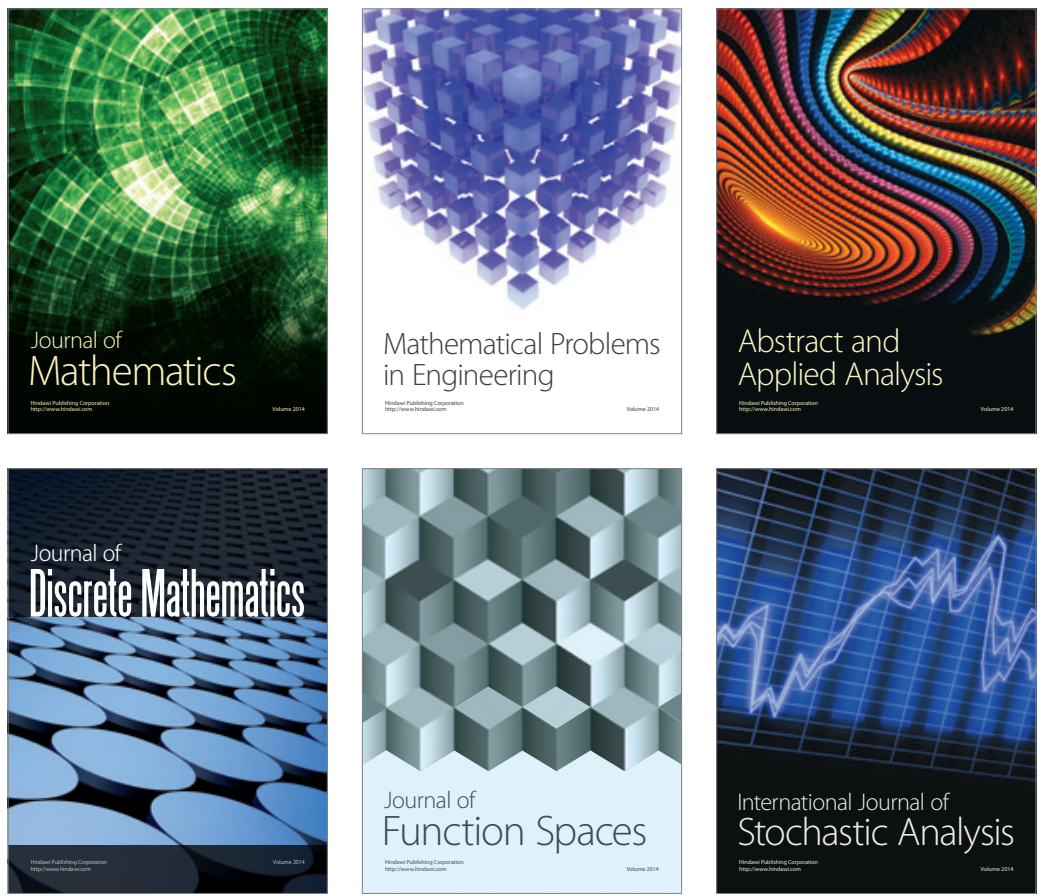

Journal of

Function Spaces

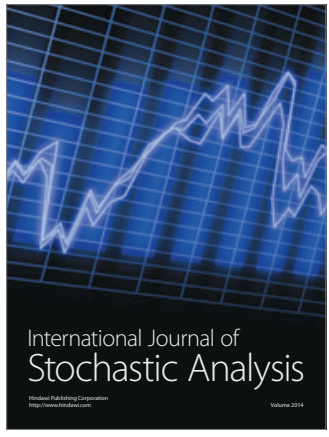

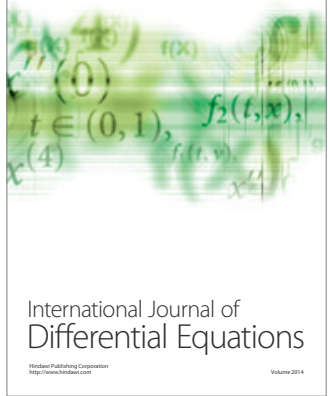
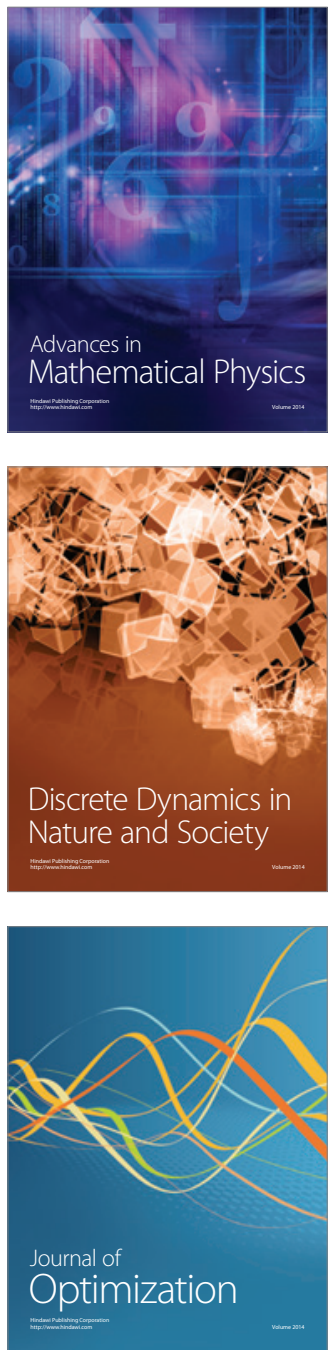